\title{
Alcoolismo em Indígenas Potiguara: Representações Sociais dos Profissionais de Saúde
}

Alcoholism In Indigenous Potiguara: Social Representations For Health Professionals

Alcoholismo En Potiguara Indígenas: Representaciones Sociales Para Profesionales De La Salud

\section{Silvana Carneiro Maciel, Rita de Cássia Cordeiro de Oliveira \& Juliana Rízia Félix de Melo
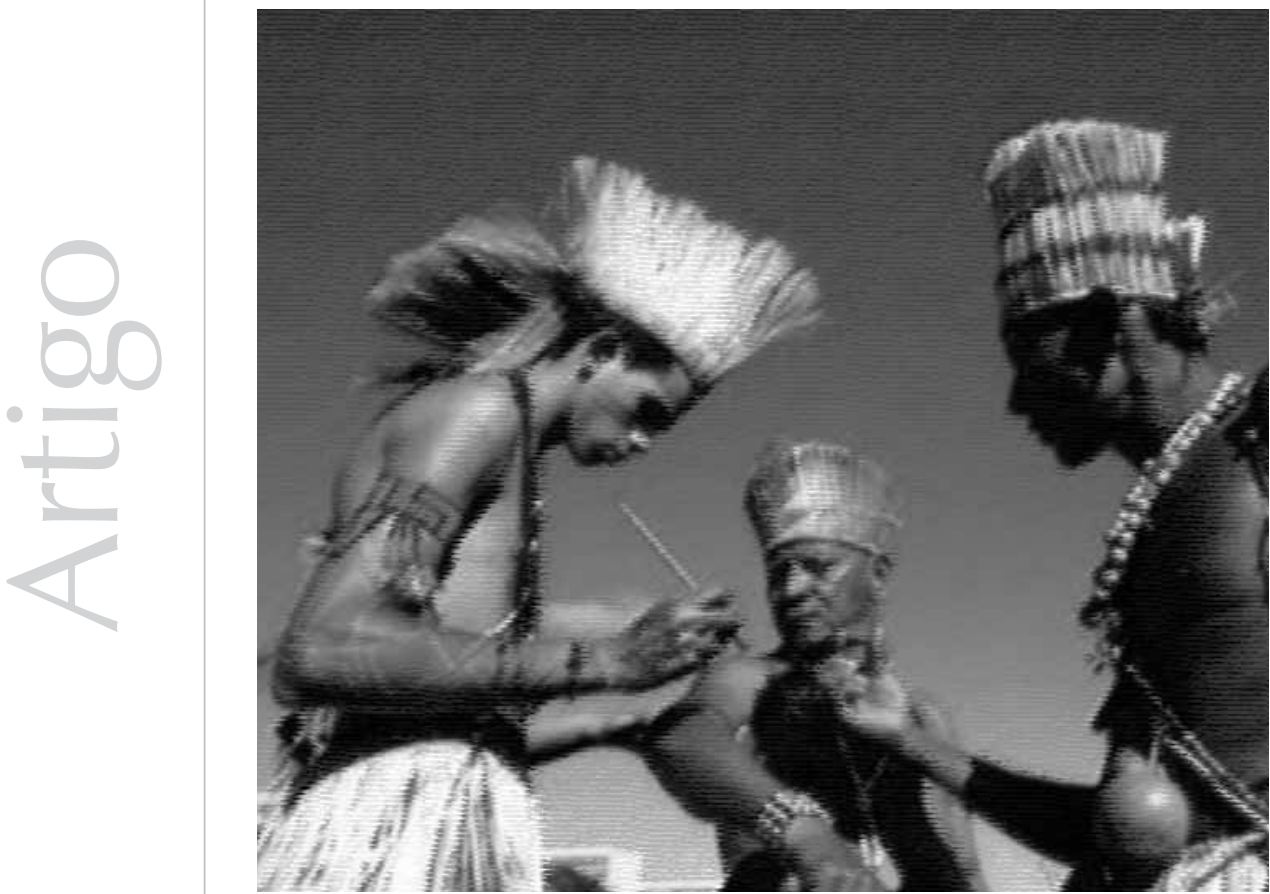
Resumo: Este estudo investigou as representações sociais de profissionais de saúde acerca do uso do álcool pelos índios Potiguara e foi realizado na comunidade Potiguara do Estado da Paraíba, nos polos-base situados nos Municípios de Rio Tinto, Marcação e Baía da Traição. A amostra compreendeu 21 profissionais de saúde, integrantes da Equipe Multidisciplinar em Saúde Indígena, e os dados foram coletados por uma entrevista semiestruturada e analisados através do software ALCESTE. O uso abusivo do álcool foi assinalado como uma grave problemática de saúde que atinge essa população, a exemplo das DSTs/AIDS e da gravidez precoce. $\mathrm{O}$ alcoolismo apareceu vinculado à diversão e ao lazer, sendo suas causas atribuídas ao processo de aculturação desses índios. Essa questão foi agravada pelo fato de os indígenas viverem próximos a usinas e engenhos, em áreas litorâneas, o que favoreceu o acesso a bebidas alcoólicas. Os participantes mostraram desconhecimento acerca dos serviços ofertados aos usuários dependentes, assinalando a importância de maior preparo e de conhecimento da cultura Potiguara, a fim de resgatá-la e de promover melhores condições de vida para essa comunidade. Sugere-se a realização de novos estudos, visando a dimensionar melhor a questão do alcoolismo nos Potiguaras e a contribuir para a implantação de serviços de Atenção Básica à Saúde em sua comunidade.

Palavras-chave: Representação social. Alcoolismo. Indios. Profissionais de saúde. Drogas.

\begin{abstract}
This study investigates the social representations of health professionals about the use of alcohol among the indians Potiguara. It was conducted in the community, in the Base Poles located in the municipalities of Rio Tinto, Marcação and Baia da Traição. The sample consisted of 21 health professionals, members of the Multidisciplinary Team on Indigenous Health. Data were collected by a semistructured interview and analyzed through the use of the software Alceste. The abuse of alcohol was reported as a serious health problem that affects this population, such as DSTs/AIDS and early pregnancy. Alcoholism appeared linked to entertainment and leisure, and its causes were attributed to the acculturation process of these indians. This issue was worsened by the fact that the indians lived near the factories and mills in coast areas, what made the access to liquor easier. The participants showed ignorance about the services offered to dependent users, highlighting the importance of better preparation and knowledge of the culture Potiguara in order to rescue it and to promote better living conditions for this community. It is suggested that further studies are made in order toevaluate the use of liquor by the Potiguaras and to contribute to the implementation of Primary Health Care services in the community.
\end{abstract}

Keyword: Social representacion. Alcoholism. Indians. Health professionals. Drugs.

Resumen: Este estudio investigó las representaciones sociales de profesionales de salud, acerca del uso del alcohol por los indios Potiguara. Fue realizado en la comunidad Potiguara del Estado de Paraíba, en los polos base situados en los municipios de Rio Tinto, Marcação y Baía da Traição. La muestra comprendió 21 profesionales de salud, integrantes del Equipo Multidisciplinaria en Salud Indígena. Los datos fueron colectados por una entrevista semiestructurada y analizados a través del software ALCESTE. El uso abusivo del alcohol fue señalado como una grave problemática de salud que afecta a esa población, a ejemplo de las ETS/SIDA y del embarazo precoz. El alcoholismo apareció vinculado a la diversión y al ocio, siendo sus causas atribuidas al proceso de aculturación de esos indios. Esta cuestión fue agravada por el hecho de que los indígenas viven próximos a fábricas e ingenios, en áreas de litoral, lo que favoreció el acceso a bebidas alcohólicas. Los participantes mostraron desconocimiento acerca de los servicios ofertados a los usuarios dependientes, señalando la importancia de mayor preparación y conocimiento de la cultura Potiguara, a fin de rescatarla y promover mejores condiciones de vida para esta comunidad. Se sugiere la realización de nuevos estudios, visando dimensionar mejor la cuestión del alcoholismo en los Potiguaras y contribuir para la implantación de servicios de Atención Básica a la Salud.

Palabras clave: Representación social. Alcoholismo. Indios. Profesionales de salud. Drogas.

O fenômeno do alcoolismo é considerado um dos maiores problemas de saúde pública no Brasil. Em nível biopsicossocial, as consequências do uso abusivo de álcool abrangem homicídios, suicídios, agressões, conflitos interpessoais e acidentes de trânsito, entre outras. Uma das causas apontadas para o favorecimento do elevado consumo de álcool é a facilidade com que essa droga é disponibilizada. Na medida em que é considerado lícito, incentivado e comercializado livremente, o álcool se torna uma das substâncias mais experimentadas pelos brasileiros (Santos \& Veloso, 2008).

A partir da $8^{a}$ Conferência Mundial de Saúde, realizada em 1986, o tema específico do alcoolismo foi incorporado à Classificação 
Como apontam

Guimarães e

Grubits (2007),

a expansão

das frentes

econômicas

(extrativismo

e trabalho

assalariado

temporário) vem

ameaçando

a integridade

tanto do meio

ambiente,

nos limites dos

seus territórios,

quanto dos seus

saberes e da sua identidade.
Internacional das Doenças (CID) como síndrome de dependência de álcool. Atualmente, a Organização Pan-Americana de Saúde e a Organização Mundial de Saúde (OPAS/OMS, 2001) definem o alcoolismo como uma das patologias que mais acometem indivíduos e coletividades, configurando-se como um grave problema de saúde pública. Em virtude de se caracterizar como fenômeno de grande complexidade, o alcoolismo vem se colocando como um desafio frente aos profissionais das diversas áreas, os quais não conseguem atuar de forma objetiva. Segundo Barros (2004), uma das consequências da complexidade do alcoolismo é a imprecisão no seu diagnóstico. Frequentemente, esse diagnóstico apresenta-se subestimado, além de ser realizado quando o indivíduo já está em um estágio avançado de dependência, com sérios acometimentos físicos, psíquicos e sociais.

De acordo com Palitot (2005), o uso do álcool faz parte de inúmeras festividades e relações sociais, sendo vivenciado nas mais diversas culturas. Atualmente, o uso abusivo dessa substância vem afligindo sobremodo as comunidades indígenas brasileiras. Entre essas comunidades, destaca-se a dos Potiguaras, como a única reconhecida do Estado da Paraíba, ao mesmo tempo em que representa a maior do Nordeste etnográfico e uma das maiores do Brasil. Sua população é de 13.790 índios, sendo que 2.061 deles são desaldeados, e residem em outras cidades, enquanto os demais, aldeados, estão distribuídos em 29 aldeias nos Municípios de Baía da Traição, Marcação e Rio Tinto (DSEl/ Potiguara, 2008).

A comunidade indígena Potiguara sobrevive da agricultura, da pesca, do artesanato e de outras atividades, e enfrenta situações distintas de tensão social e vulnerabilidade. Como apontam Guimarães e Grubits (2007), a expansão das frentes econômicas (extrativismo e trabalho assalariado temporário) vem ameaçando a integridade tanto do meio ambiente, nos limites dos seus territórios, quanto dos seus saberes e da sua identidade.

Palitot (2005) destaca que, por estarem situadas próximas a engenhos e usinas, e por se encontrarem em área litorânea, as aldeias dos Potiguaras passaram a conviver com o turismo desordenado. Isso contribuiu para a instalação de bares e restaurantes dentro das aldeias, favorecendo a aquisição de hábitos e costumes diferentes dos seus habitantes, que começaram a fazer uso abusivo de bebidas alcoólicas. Outro fator de agravamento da saúde indígena foi a transmissão de doenças, principalmente as sexualmente transmissíveis (DSTs) e a AIDS, uma vez que tais mudanças de hábitos e de cultura deveu-se, também, ao fato de não indígenas residirem dentro das aldeias.

Em decorrência da pulverização característica do mundo globalizado e da introjeção de hábitos e costumes diferentes, a etnia Potiguara acaba sendo motivo de preocupação dos seus integrantes e dos profissionais que com ela trabalham. Sendo assim, este estudo teve como objetivo investigar as representações sociais dos profissionais de saúde do DSEl/ Potiguara acerca do uso do álcool e do alcoolismo nessa comunidade indígena no Estado da Paraíba.

\section{Alcoolismo na comunidade indígena e suas representações sociais}

De acordo com a Fundação Nacional de Saúde (FUNASA, 2000), o alcoolismo está entre as enfermidades mais comuns nos grupos indígenas brasileiros, com destaque para as Regiões Nordeste, Centro-Oeste, Sudeste e Sul, tendo como agravante a aproximação entre as populações indígenas e as não indígenas. Segundo Souza e Garnelo (2007), o contato interétnico teve início há mais de três séculos e propiciou a introdução da 
bebida destilada nas comunidades indígenas, ocasionando mudanças na organização dessas sociedades, com modificações mais amplas na sua cultura.

Dados da OPAS/OMS (2001) revelam que o alcoolismo afeta cerca de $10 \%$ da população mundial. No que se refere à população indígena, Souza e Aguiar (2001) relatam que a proporção do consumo de bebidas entre ela é maior do que o da população não indígena, chegando a atingir 17,6\% em uma população aldeada do Mato Grosso do Sul.

Ferreira (2004) realizou um estudo com índios Mbyá-Guarani, no Rio Grande do Sul, a fim de investigar a relação entre o consumo do álcool e a diversidade cultural. Verificou que o consumo de álcool é influenciado pelas particularidades culturais de cada aldeia, variando de acordo com o contato interétnico e com as estratégias e mecanismos de enfrentamento dessas comunidades diante da pressão exercida pelo contato.

A FUNASA (2002) alerta que o alcoolismo é um dos problemas cada vez mais frequentes nas comunidades indígenas que têm um relacionamento mais estreito com a população regional. Em virtude disso, visando à reestruturação das estratégias governamentais de atenção à saúde indígena, o Ministério da Saúde instituiu, através da Portaria de no. 254, de 31 de janeiro de 2002, a Política Nacional de Atenção à Saúde dos Povos Indígenas (PNASPI). O objetivo é assegurar aos povos indígenas o acesso à atenção integral à saúde, de acordo com os Princípios e as Diretrizes do Sistema Único de Saúde (SUS). Tais princípios contemplam as diversidades social, cultural, geográfica, histórica e política dessas populações, de modo a beneficiar a superação dos fatores que as tornam mais vulneráveis aos agravos de saúde, certificando a eficácia de sua medicina tradicional e o direito de preservarem a sua própria cultura.
Para o alcance desses objetivos, os serviços de atenção à saúde dos povos indígenas foram organizados na forma de Distritos Sanitários Especiais Indígenas (DSEI). Segundo dados da FUNASA (2008), o DSEI/Potiguara contava com 167 profissionais de saúde, distribuídos em equipes multidisciplinares formadas por médicos, enfermeiros, odontólogos, auxiliares de enfermagem e agentes indígenas de saúde, entre outros. Além do DSEI/Potiguara, a comunidade pode contar com outra instância de atendimento, constituída por três PolosBase situados, cada um deles, nos Municípios de Marcação, Baía da traição e Rio Tinto, os quais funcionam no nível local, onde a atenção primária e os serviços de referência ocorrem.

A PNASPI também garante que, para a melhoria do estado de saúde dos povos indígenas, não deverá ocorrer uma substituição de seus sistemas tradicionais de saúde, baseados em uma concepção holística do indivíduo, pelos conhecimentos e tecnologias da biomedicina ocidental. Preferentemente, o que deve ser almejado é uma articulação entre esses saberes, valorizando a diversidade cultural e social dos índios e o seu direito a ela.

Nesse sentido, ao abordar a problemática do alcoolismo na comunidade indígena Potiguara, os profissionais de saúde devem estar atentos a dois aspectos característicos dessa população: por um lado, devem levar em conta que esses índios já possuem um contato interétnico acentuado, e, por outro, devem tentar preservar a especificidade da sua cultura, com suas crenças, costumes e representações.

Uma forma de abordar essa especificidade é através da teoria das representações sociais, tal como foi concebida por Moscovici (1978). As representações sociais consistem em um tipo de conhecimento socialmente construído, elaborado no âmbito dos fenômenos comunicacionais, que repercutem sobre as 
interações e as mudanças sociais na própria cultura (Maciel, Moreira, \& Gontiés, 2001). Como esclarece Minayo (1984), uma vez que são portadoras dos interesses específicos dos grupos e das classes sociais, as representações sociais devem sempre ser remetidas ao seu contexto de produção.

Desse modo, as representações sociais do alcoolismo, por parte dos profissionais de saúde que trabalham nas comunidades indígenas, consistem nas suas compreensões e explicações feitas a partir de uma releitura significativa do mundo, com uma linguagem compartilhada com os outros membros do grupo social em que estão inseridos. A esse respeito, Guimarães e Grubits (2007) apontam que, devido à escassez de estudos epidemiológicos sobre o alcoolismo em populações indígenas, há uma necessidade imperativa de mais pesquisas que permitam melhor dimensionamento do problema e melhor caracterização das especificidades culturais de cada etnia. Na concepção de Langdon (2001), há desconhecimento e falta de estudos que dimensionem o consumo de bebidas alcoólicas na população indígena, o que ocasiona limitações no desenvolvimento de ações preventivas e de propostas de trabalho adequadas a essas comunidades.

Tendo em vista essa rede de problemas que acarretam o agravamento do uso do álcool na população indígena Potiguara e a especificidade cultural dessa etnia, este trabalho foi desenvolvido com o intuito de compreender e investigar os fatores relacionados que sustentam o uso/abuso do álcool nessa comunidade. De modo mais específico, o trabalho pretende verificar as representações sociais dos profissionais de saúde que trabalham com essa população, a fim de procurar subsídios para entender essa dinâmica social e gerar dados que possam auxiliar os órgãos competentes na implantação de serviços de Atenção Básica à Saúde.

\section{Método}

\section{Tipo de estudo}

Esta é uma pesquisa de cunho exploratório, que utilizou um delineamento qualitativo, com uma amostragem não probabilística intencional. Esse tipo de técnica amostral não tem interesse na generalização dos resultados, possuindo antes um caráter investigativo, e interessa-se apenas pela opinião de elementos da comunidade sobre o assunto estudado, elecando um número mais reduzido de depoentes, em função da saturação dos resultados. No caso específico da presente investigação, essa técnica permite a apreensão das representações dos profissionais de saúde acerca do uso/abuso do álcool na população dos Potiguaras.

\section{Local}

O presente estudo foi realizado no Estado da Paraíba, nos Polos-Base do DSEI/Potiguara, situados nos Municípios de Rio Tinto, Marcação e Baía da Traição, sendo um polo em cada localidade. Essas terras indígenas ocupam um espaço de aproximadamente 34.000ha e estão localizadas, respectivamente, a 70 km, 77 km e 100 km da capital do Estado (João Pessoa).

\section{Amostra}

A amostra compreendeu 21 profissionais de saúde, abrangendo médicos, enfermeiros, dentistas, fonoaudiólogos e psicólogos, além de outros profissionais de nível técnico, sendo que todos eles foram selecionados de forma não probabilística e de conveniência. Os participantes eram de ambos os gêneros, com idades variando entre 21 e 52 anos e com nível de escolaridade entre $2^{\circ}$ grau e pósgraduação. Em outros aspectos, como tempo de atendimento a índios, religião, profissão e estado civil, os participantes apresentavam escores variados. 


\section{Instrumento para a coleta de dados}

Para a coleta de dados, utilizou-se uma entrevista semiestruturada, realizada com o uso de gravador, com perguntas acerca do uso/abuso do álcool na comunidade indígena. A entrevista também continha dados sociodemográficos, os quais serviram para a caracterização da amostra.

\section{Procedimentos éticos}

Para a execução desta pesquisa, foi obedecida a Resolução n 196/96, do Conselho Nacional de Saúde, que estabelece as normas e as diretrizes para a realização de estudos com seres humanos, tendo os participantes assinado um Termo de Consentimento Livre e Esclarecido. O projeto foi aprovado pelo Conselho Distrital Indígena (CONDISI), pelo cacique geral dos Potiguaras, pela FUNASA e pela $\mathrm{FUNAI}$, sendo os pesquisadores autorizados a entrar nas terras indígenas para a execução da pesquisa, que contou ainda com a aprovação do Comitê de Ética em Pesquisa do Hospital Universitário Lauro Wanderley, da Universidade Federal da Paraíba - UFPB (CEP/HULW - protocolo no. 227/09).

\section{Procedimentos para a coleta dos dados}

Após o contato com o DSEl/Potiguara, na FUNASA de João Pessoa, pôde-se ter acesso aos Polos-Base de Rio Tinto, Marcação e Baía da Traição, onde foram realizadas as entrevistas. Os participantes foram esclarecidos sobre o conteúdo e o caráter voluntário da pesquisa, e as entrevistas foram feitas individualmente, com o uso de um gravador.

\section{Análise dos dados}

Os dados foram submetidos à análise de discurso, realizada a partir do software ALCESTE (Análise Lexical por Contexto de um Conjunto de Segmentos de Texto). Trata-se de um software de análise de dados textuais, que tem como objetivo obter uma classificação estatística de enunciados simples do corpus estudado. Essa classificação é feita levando-se em conta a distribuição de palavras dentro dos enunciados, a fim de apreender aquelas mais características. No caso deste estudo, o corpus foi constituído pelas entrevistas realizadas.

Camargo (2005) chama a atenção para o procedimento que deve ser adotado ao se utilizar esse programa na análise de um conjunto de entrevistas, quando geralmente são produzidos textos mais extensos. Segundo ele, cada uma das entrevistas deve ser considerada como uma Unidade de Contexto Inicial (UCI), sendo suficientes entre 20 e 30 delas, desde que o conjunto seja homogêneo.

As classes podem apontar as relações entre as características dos autores do material textual e as variáveis preestabelecidas pelo pesquisador. No presente estudo, tais características e variáveis se concentraram ao redor de: idade, sexo, estado civil, escolaridade, profissão, religião e tempo de atendimento aos índios. Dessa forma, foi possível apreender os discursos da população estudada acerca do objeto em análise, possibilitando fazer uma investigação das representações e dos significados mais característicos de cada classe e de seus representantes.

\section{Resultados e discussão}

Como mostra o dendograma da Figura 1, o programa utilizou $51 \%$ do corpus de análise, dividido em 4 classes. A Classe 3 (álcool e prazer) e a Classe 2 (comunidade e as questões de saúde) se articulam em um 1 o eixo, enquanto a Classe 4 (concepções sobre 
o alcoolismo) e a Classe 1 (consequências socioculturais) se articulam em um $2^{\circ}$ eixo, de acordo com a ordem exposta na análise hierárquica descendente. A Classe 1 representou 25,24\% do corpus, a Classe 2 e a Classe 3 apresentaram-se, ambas, com 11,65\%, e a Classe 4 expressou $51,46 \%$ do corpus analisado. O dendograma mostra ainda o número de unidades de contexto elementar (UCE) que compõem as classes (que consistem em segmentos de texto definidos pelo ALCESTE), a descrição das variáveis que caracterizam os sujeitos ligados a elas e as palavras mais significativamente associadas, segundo o qui-quadrado $\left(\chi^{2}\right)$.

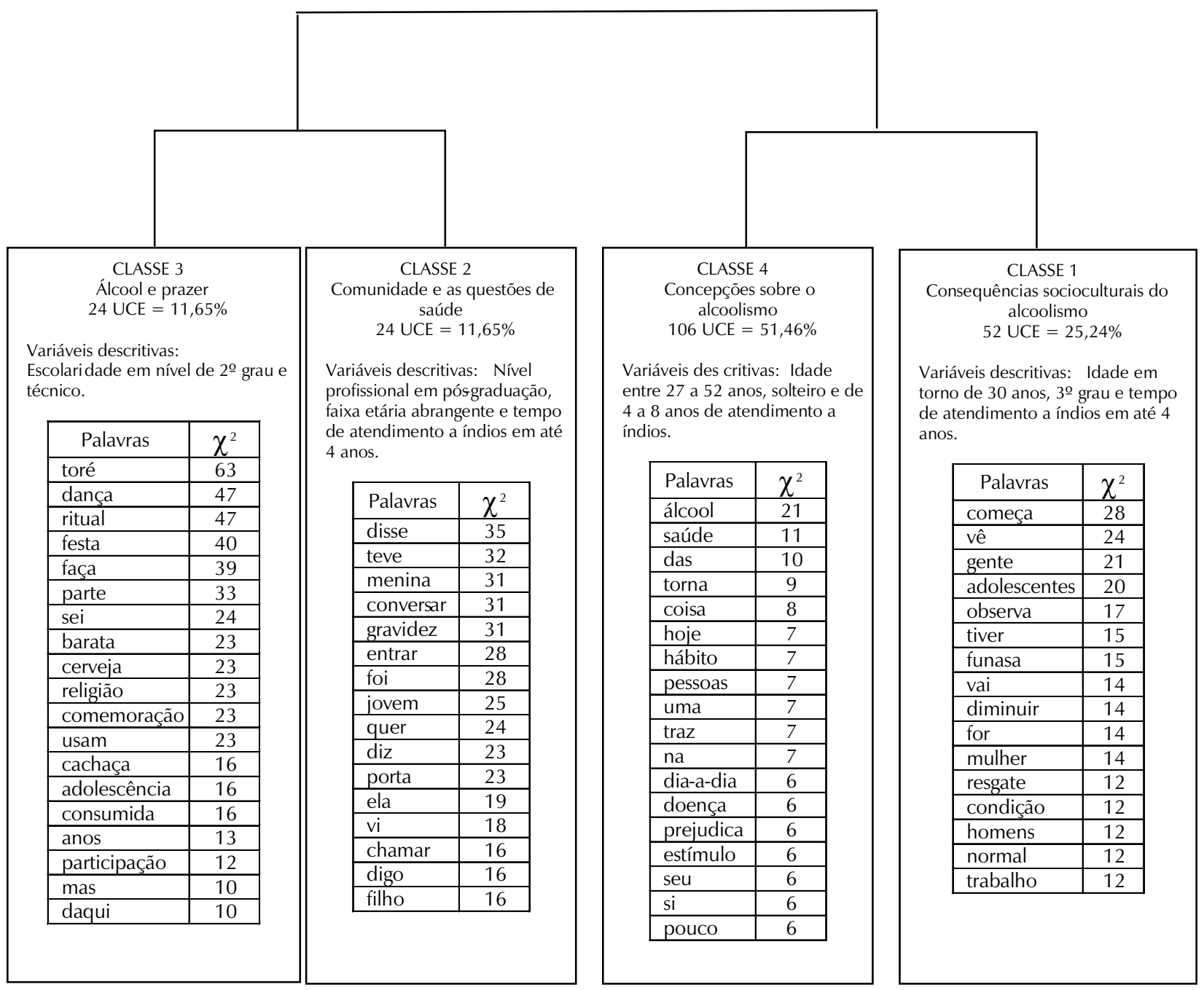

Figura 1. Dendograma das classes sobre representações sociais dos profissionais de saúde acerca do uso do álcool pelos índios Potiguara (DSEl/ Potiguara/PB, 2009)

Fonte: Dados da pesquisa

\section{Classe 3: Álcool e prazer}

Essa classe apresenta 24 UCEs (11,65\%), sendo a escolaridade, no nível de 20 grau e no nível técnico, a variável mais significativa. As palavras toré $\left(\chi^{2}=63\right)$, dança $\left(\chi^{2}=47\right)$, ritual $\left(\chi^{2}=47\right)$, festa $\left(\chi^{2}=40\right)$ e comemoração $\left(\chi^{2}=23\right)$ sugerem que o álcool está muito relacionado à diversão, 
Moonen, Maia

e Mariz (2008)

afirmam que

quase nada restou dos

padrões culturais antigos dos

índios Potiguara.

Segundo ele, o

que ainda os

lembra da sua

ascendência

indígena é

a dança do

toré, que é executada,

às vezes, em

comemorações, como na

Semana do Índio

e para dar mais

brilho às festas folclóricas. à festividade e aos rituais indígenas, como pode ser visto nos seguintes relatos:

Porque eles usam muito o álcool nas festas... e quando tem o toré, quando tem as festas desde cedo, eu acho que com mais ou menos $12 \backslash 13$ anos bebem... (ind. 13, ida. 45, sexo masc.);

Vou ser sincera contigo, eu nunca assisti um ritual, eu tô aqui com eles há 7 anos e 9 meses, mas nunca assisti nenhum... (ind. 07 , ida. 37 , sexo masc.).

Em um estudo realizado em Pernambuco sobre as representações sociais dos agentes comunitários de saúde acerca do uso do álcool, Castanha e Araújo (2006) também encontraram a diversão e o prazer como associados a essa prática.

Além dessa questão, observa-se, através dos discursos, um desconhecimento da cultura indígena Potiguara por parte dos profissionais entrevistados, como pode ser demonstrado no relato a seguir: "O ritual indígena que a gente sabe que tem aqui é o toré... do ritual, mesmo, eu não sei explicar melhor pra você" (ind. 06, ida. 52, sexo fem.).

Esse relato evidencia a necessidade de maior conhecimento acerca da diversidade social e cultural indígena, tal como é recomendado pelos princípios, calcados no respeito e na valorização, pregados pela FUNASA (2002). O conhecimento torna-se um pressuposto básico para intervenções visando não somente ao resgate da cultura indígena mas também à solução dos problemas relacionados ao alcoolismo e ao aumento da qualidade de vida dos índios. Porém, como advertem Barboza e Craveiro (2004), fica inviável fazer esse resgate se os próprios profissionais não conhecem essa cultura. Somente através do reconhecimento da identidade coletiva e individual e do fortalecimento organizacional, cultural e social indígena é que se dará o resgate da cidadania. Além dessas questões, o uso das palavras toré, dança e ritual sugerem o uso do álcool vinculado ao Toré, que é uma festa comemorativa da cultura Potiguara. Como revelam alguns segmentos de textos a seguir, essa festa é percebida como a única manifestação que caracteriza e que legitima o ser índio nessa comunidade:

Tem o toré, abril é o mês deles, é o mês de comemoração pra eles, então assim, se é comemoração, é festa, se é festa, é álcool (ind. 01, ida. 25, sexo fem);

$\mathrm{Na}$ dança do toré, em alguns eventos comemorativos, eles consomem nas festas comemorativas (ind. 09, ida. 27, sexo fem.); O toré é a mais representativa dos índios daqui da região, eles fazem todo aquele... Um almoço, tudo mais com as famílias e crianças, mas depois vêm e usam. Porque é como eu te falei, é como se fosse o lazer, fizesse parte, então apesar de estar ligada, a dança estar ligada com a religião, mas já faz parte do cardápio, por trás, não no menu, não no momento especificamente da dança, isso aí não, mas é um motivo, aproveitam que estão todos reunidos em torno de algo, então acaba sendo um motivo pra se consumir álcool (ind.10, ida. 30, sexo fem.).

Moonen, Maia e Mariz (2008) afirmam que quase nada restou dos padrões culturais antigos dos índios Potiguara. Segundo ele, o que ainda os lembra da sua ascendência indígena é a dança do toré, que é executada, às vezes, em comemorações, como na Semana do Índio e para dar mais brilho às festas folclóricas. Em 1969, continua o autor, houve uma tentativa espontânea de dançar o toré na aldeia São Francisco, que quase terminou em briga devido a desacordos com relação ao ritmo, ao texto e à coreografia. Posteriormente, através do Conselho Indigenista Missionário (CIMI), os Potiguara aprenderam que precisavam exibir símbolos de indianidade, pois, como índios, precisavam ter uma cultura indígena. A partir daí, o toré passou a ocorrer publicamente, como expressão dessa indianidade, em encontros e eventos em que há a presença de pessoas estranhas à comunidade: 
Dança que é muito típica, o toré, que é muito típico da população Potiguara (ind. 17, ida. 27, sexo fem.); Você chega às aldeias num tem quem distinga entre um índio e um branco. Aí você chega numa festa do toré, ou outra festa que tenha um ritual, num digo nem o toré, mas uma festa que tem um ritual, aí você já sente, já marca aquilo dali, você chega, sente mesmo, quando eles estão dançando, eu digo mesmo pra mim, agora sim, estou trabalhando com índio, porque aí chama atenção (ind. 21, ida. 44, sexo fem.)

Barboza e Craveiro (2004) indicam que os Kaingáng ingeriam bebidas fermentadas, com baixo teor alcoólico, em momentos específicos, como parte de seus rituais. Eram encontros caracterizados por grandes estados de embriaguês, os quais despertavam a consciência mítica grupal. Todavia, eram ocasiões que serviam para a integração e não configuravam patologia ou dependência, pois a bebida era consumida até o final, e logo terminava a bebedeira. Atualmente, constatase que esse costume cultural se perdeu, ao longo da colonização efetuada pelo homem branco.

Com relação aos Potiguara, os profissionais escolheram a cachaça $(95,2 \%)$ como a bebida alcoólica mais consumida na comunidade, ficando em segundo lugar a cerveja $(9,5 \%)$. Os termos barata, cachaça e consumida, que aparecem na fala dos entrevistados, indicam que a cachaça é a bebida alcoólica mais consumida por ser a mais barata: "Geralmente é bem jovem que se inicia o uso do álcool. Cachaça é a bebida alcoólica mais consumida porque é a mais barata, é a cachaça mesmo" (ind. 04, ida. 38, sexo masc.).

Esse dado corrobora o que dizem Barboza e Craveiro (2004), no sentido de que os índios consomem, de preferência, a cachaça. Alguns tomam vinho e cerveja, porém não os consideram bebidas alcoólicas. Segundo esses autores, produtos como desodorante e álcool de farmácia também são consumidos por alguns membros da comunidade; outros estudos, como o de Assis (2007), também confirmam esses resultados.

Palitot (2005) afirma que o fato de os Potiguara estarem situados próximos a usinas e engenhos favoreceu o uso abusivo de bebidas alcoólicas. Além disso, o fato de viverem em áreas litorâneas, de grande acesso turístico, contribuiu para a instalação de bares e restaurantes dentro das aldeias, facilitando o processo de alcoolização da comunidade. Na pesquisa elaborada por ( R. Oliveira 2009) com índios Potiguara, observou-se que $41,8 \%$ dos entrevistados afirmaram ter pelo menos um membro da família que fazia uso de bebida alcoólica. No que se refere às consequências do usolabuso do álcool, 27,3\% disseram que a bebida traz problemas para toda a família, inclusive informando casos de óbito devido à cirrose hepática $(5,5 \%)$.

\section{Classe 2: A comunidade e as questões de saúde}

A Classe 2 apresenta 24 UCEs, que representam 11,65\% do corpus analisado. Os participantes que mais contribuíram para essa classe tinham nível de escolaridade com pósgraduação, faixa etária abrangente e tempo de atendimento na comunidade indígena de até 4 anos.

Aqui a presença de palavras como menina $\left(\chi^{2}=31\right)$, gravidez $\left(\chi^{2}=31\right)$ e jovem $\left(\chi^{2}=25\right)$ indica o alcoolismo associado a questões de saúde da comunidade. Mas os discursos também estão ligados a outras problemáticas da comunidade Potiguara, tais como relacionamentos sexuais, doenças sexualmente transmissíveis e gravidez precoce. Esses temas mostraram-se bastante presentes nas falas dos participantes, constituindo um motivo de preocupação por parte da equipe dos profissionais de saúde:

O álcool é uma droga, é um dos vícios que acarreta, é uma cadeia, vem o álcool, ele num se satisfaz só com o álcool, depois vem 
uma droga, tem usuários, e outros fatores da doença em si, que é a depressão, que a depressão (ind. 21, ida. 44, sexo fem.); Quando você pega uma pessoa que teve relação sexual sem camisinha, a gente conversa, explica, explica que aquele jovem está no grupo de risco, a gente diz a ele não tem a menor justificativa, porque hoje se você entrar aí na porta do Forte, você vai ver uma bandeja, parece até uma brincadeira, mas é uma bandeja, mesmo, cheia de preservativos, eu costumo brincar e chamar de bombonière. (...) Tem menina que, quando eu entrei aqui, que eu nunca vi isso na minha vida, de 10 anos grávida, então foi um choque pra mim, como também esse menino que queria ser gay (ind. 13, ida. 32, sexo masc.)

O termo porta também aparece em um contexto em que o álcool é tido como gerador de outros problemas para a comunidade. Nesse sentido, aparece como uma porta de entrada, inclusive para acidentes de trânsito e para as DSTs\AIDS:

Mas a gente sabe que esse é um problema social grave (alcoolismo), que só vai levar porta de entrada para outros problemas, pra acidentes de trânsito, cada vez mais a lei sendo endurecida (ind. 05, ida. 41, sexo masc.);

A questão de doenças, tem muitos casos de AIDS aqui, tem muitos casos de doenças, DST, é tanto que tem até uns cartazes de gravidez na adolescência, DST e AIDS, DST, sexo, contra a violência sexual, a gente tem muito caso aqui de estupro... (ind. 01, ida. 25, sexo fem.).

Em uma pesquisa realizada com profissionais do DSEI/Potiguara sobre a questão da saúde, Conceição (2007) destaca dois aspectos que fazem com que a prática do uso do álcool seja preocupante. O primeiro é devido ao alto índice de consumo, que, segundo esses profissionais, vem crescendo assustadoramente, principalmente entre os jovens. O segundo diz respeito aos efeitos provocados pela bebida, tais como: problemas de saúde, inclusive DSTs/ HIV, e problemas sociais.

\section{Classe 4: Concepções sobre o alcoolismo}

Essa classe apresentou um total de 106 UCEs, o que representa $51,46 \%$, ou seja, a maior parte das UCEs classificadas. Os conteúdos mais significativos dos relatos mostraram-se associados a participantes que tinham idade entre 27 a 52 anos, solteiros e 4 a 8 anos de atendimento a índios. Pode-se notar que o vocábulo álcool $\left(\chi^{2}=21\right)$ está ligado a uma diversidade de outras palavras, tais como ruim, distúrbio, algo facilitador nas relações interpessoais, droga, hábito, vício e um meio de diversão:

(...) Acho que é um distúrbio que há na pessoa em consequência de vários fatores, como depressão e falta de amor. (...) Justamente, porque é um vício, é a busca do lazer na bebida. Aquela sensação de prazer, de alegria e tudo (ind. 19, ida. 24, sexo fem.)

A palavra saúde $\left(\chi^{2}=11\right)$ aparece em um contexto em que o álcool é descrito como algo que já faz parte da comunidade, mas que é nocivo ao povo indígena:

O álcool, eu vejo assim como uma questão de calamidade na questão da saúde do povo indígena, então é uma coisa que hoje se tornou indispensável (...). Porque o álcool estimula mais quando a pessoa está bêbada a fazer muitas coisas. Pra mim, eu não acho que seja bom pra saúde, não (...) É uma coisa ruim que traz muitas consequências para as pessoas (...) (ind. 08, ida. 50, sexo fem.)

Esses dados também foram encontrados por Conceição (2007) ao analisar a percepção dos profissionais de saúde sobre o consumo de bebidas alcoólicas pelos índios Potiguara. Os resultados mostraram que o alcoolismo era visto como uma doença, um vício, uma dependência.

Desse modo, observa-se que ainda há predominância do entendimento do alcoolismo como um fenômeno de natureza físico-individual. Por esse ponto de vista, o alcoolismo consiste em uma dependência 
biológica que causa comportamentos desviantes, e traz consequências negativas tanto para o indivíduo que usa abusivamente o álcool quanto para o seu grupo social. $\mathrm{Na}$ perspectiva da biomedicina, o alcoolismo vem sendo definido como uma doença que se manifesta igualmente em todas as culturas. Por sua vez, a Psicologia considera que a dependência alcoólica ocorre no nível individual e pode ser atribuída a causas de ordem psíquica (Langdon, 2001).

Nota-se, portanto, um desprezo em relação ao campo coletivo-social, segundo o qual se considera que o alcoolismo seja construído através do tempo e do contato entre sociedades diferentes e não paritárias (Oliveira, 2001). Conforme Souza e Garnelo (2007), o enfoque do alcoolismo como doença acaba deixando de lado aspectos importantes que estão a ele relacionados. Os autores ressaltam a necessidade de contextualizar esse assunto na cultura e na história, devendo-se verificar o que significa o ato de beber em um determinado tempo e grupo social. Dentro dessa perspectiva, Assis afirma:

O ambiente social e cultural é provavelmente a mais importante influência sobre o ato de beber, pois condiciona o tipo de bebida a ser consumida, como se bebe, onde beber, com quem beber, como se comportar e o que se espera de quem bebe. O ambiente inclui fatores como o que as pessoas pensam e creem sobre o álcool, as regras locais e, além disso, quanto beber, como conseguir e utilizar a bebida. O ambiente social e cultural faz toda a diferença. Isso pode causar maior ou menor dificuldade para a pessoa tornar-se ou não dependente do álcool (2007, p.111)

As palavras hábito $\left(\chi^{2}=07\right)$ e dia a dia $\left(\chi^{2}=06\right)$ sinalizam a presença intensa do alcoolismo na comunidade indígena, como mostram algumas UCEs a seguir:
É o hábito de beber constante, acorda bebendo, tudo é motivo pra uma bebidinha, aí, com isso, as pessoas bebem no seu dia a dia como seu pão de cada dia. O álcool se torna como se fosse o pão de cada dia, troca a comida por bebida (ind. 15, ida. 35, sexo fem.) O álcool pra eles se tornou uma coisa usual, muitos são viciados... (ind. 09, ida. 27 , sexo fem.).

Como meio de conscientizar a população sobre o assunto, os participantes da presente pesquisa apontam, como possibilidades de controle do uso abusivo do álcool, o esporte (a saída do sedentarismo), o lazer e a educação, além de sugerirem a realização de palestras educativas:

Palestras educativas, preventivas, também incentivar eles ao esporte, pra mudar o ritmo deles, eu acho que está faltando lazer, incentivo deles se modificar, a vida deles, eu acho que o sedentarismo também leva a isso (ind. 09, ida. 27, sexo fem.)

Essas representações demonstram uma visão do alcoolismo, que inclui suas causas, consequências e tratamento, totalmente ancorada nas questões culturais do homem branco, desvinculada da cultura indígena. Pode-se considerar que a própria prática de esportes e as palestras educativas estão ancoradas em uma perspectiva de aculturação dos índios e de sua dominação pela cultura dos brancos, tal como ocorreu com o episódio da sua catequização.

\section{Classe 1: Consequências socioculturais do alcoolismo}

Essa classe contém 52 UCEs, representando $25,24 \%$ do corpus analisado, sendo melhor descrita por indivíduos com idade por volta dos 30 anos, que possuem o 3 o grau e que estão atendendo índios por um período de tempo de, no máximo, 4 anos. 
Nessa categoria, os termos mais significativos apontam representações sociais das causas do alcoolismo ligadas a questões socioculturais e econômicas, tais como a ociosidade por falta de emprego e a baixa qualidade de vida:

Pelo menos aqui na comunidade nossa, na aldeia, a gente vê que é fruto até da ociosidade; a gente observa que a maioria da população, principalmente os homens, tem uma escassez muito grande aqui de emprego. (...) Então, causa uma desestrutura naquele lar, e aquelas crianças e adolescentes que estão ali no contexto também vão ser acometidas por essa patologia. Acaba virando mesmo um ciclo vicioso (ind. 14, ida. 30, sexo fem.)

Segundo Conceição (2007), são vários os motivos apontados pelos profissionais de saúde do DSEI/Potiguara que levam os índios a buscar o consumo de bebidas alcoólicas. Entre eles, destacam-se: a convivência social com o branco, a perda de identidade, a cultura, a hereditariedade, a tristeza, a autoafirmação, os problemas econômicos, a ociosidade, a falta de trabalho e a preguiça. É interessante perceber que, apesar da fusão cultural ocorrida historicamente entre europeus e indígenas, negros e, mais tarde, asiáticos, o preconceito ainda continua existindo em relação a essas populações, o que acaba por marginalizar centenas de brasileiros (T. Oliveira, 2009).

Na presente pesquisa, observou-se que, entre as consequências do uso do álcool, os profissionais de saúde representam-no como gerador de problemas físicos, de violência e de desestruturação familiar, que ocasiona brigas e penaliza principalmente mulheres, adolescentes e crianças. Essa classe mostrou também, como um meio para a resolução dessa problemática e para o aumento da qualidade de vida dos índios, a necessidade de se resgatar a cultura indígena (resgate, $\chi^{2}=12$ ). Para tanto, sugeriram um trabalho em conjunto, que englobasse os líderes indígenas locais, as famílias, toda a equipe de saúde e os órgãos competentes, enfim, exortando à prática de um trabalho com toda a comunidade, enfocando principalmente o aspecto econômico como central nesse processo. A seguir, algumas UCEs exemplificam o que foi dito:

Mas a gente procura trabalhar junto com as lideranças, junto com a família, com a parte da assistência social e da psicóloga, são pra dar um apoio maior pra esse tratamento. A gente vê que há um aumento muito grande da violência doméstica, da violência contra mulher, violência dos próprios adolescentes. (...) $E$, ultimamente, a gente vê que não tem tido controle em comunidade nenhuma, infelizmente, então eu acredito que com o resgate mesmo da cultura deles (ind. 14 , ida. 30, sexo fem.).

Como se pode notar, não há, nesses relatos, uma valorização da fala do próprio indivíduo que faz uso do álcool. De acordo com Teixeira, Schulze e Camargo, o planejamento de programas de saúde deve ser feito em conjunto, isto é, "entre quem padece o problema e quem deve resolver o problema" (2002, p. 352). Assim, não se pode prescindir do papel extremamente relevante da comunidade nesse processo, mas deve-se atentar para a necessidade de ouvir as pessoas que utilizam o álcool. Em última instância, são essas pessoas que devem ser consideradas fontes de estudos e pesquisas, com o intuito de identificar os fatores que sustentam a prática do uso do álcool.

\section{Considerações finais}

Os dados do presente estudo demonstraram que o uso abusivo de álcool está ligado a questões socioculturais e econômicas, assim como a outras problemáticas de saúde da comunidade Potiguara, como a gravidez na adolescência e as doenças sexuais. Constatouse, ainda, que existem representações sociais do alcoolismo vinculadas à diversão e ao lazer, atribuindo-se suas causas à ociosidade, ao incentivo social e ao processo de colonização/ aculturação dessa população indígena. Esses 
resultados corroboram as principais pesquisas da área, que relatam o uso excessivo do álcool na comunidade Potiguara, assim como as suas consequências danosas, o que torna o alcoolismo um problema grave nessa população. Não obstante, nota-se que bem pouco tem sido feito, em nível de intervenção, na área da saúde, concernente a essa problemática.

Observou-se também que, apesar de considerar excessivo o consumo de bebidas alcoólicas pelos índios Potiguara, os profissionais entrevistados evidenciaram um total desconhecimento acerca dos serviços ofertados aos usuários que se tornaram dependentes. Esse fato revela uma flagrante demonstração do quão precariamente são desenvolvidas as atividades de assistência à dependência de álcool nessa população. É preciso que haja maior preparo dos profissionais de saúde em direção ao conhecimento e ao reconhecimento da cultura indígena Potiguara, a fim de resgatá-la e de promover melhores condições de vida para essa comunidade.

Nesta pesquisa, evidenciou-se a necessidade de uma compreensão mais ampla do fenômeno abordado, visto que, na atual sociedade, o alcoolismo é um problema de saúde pública, atingindo a todos, sem distinção, e ocasionando problemas de ordem pessoal e social. Em se tratando da população indígena, percebe-se que houve uma adaptação ao modo de viver da população branca, sendo o alcoolismo uma das principais consequências dessa aglutinação cultural. No caso específico da comunidade Potiguara, essa questão é agravada pelo fato de esses índios residirem próximos a usinas e engenhos, o que favorece o acesso a bebidas alcoólicas. Além disso, os Potiguara vivem em áreas litorâneas, de grande acesso turístico, o que tem contribuído para a instalação de bares e de restaurantes dentro das aldeias, facilitando o processo de alcoolização da comunidade. Em resumo, os dados encontrados sublinham a necessidade de mais estudos na área, visando a dimensionar melhor a questão do uso do álcool pela população Potiguara e dos problemas de saúde a ele vinculados, além de gerar informações que possam servir de base para a implantação de serviços de Atenção Básica à Saúde acerca dessa problemática.

Silvana Carneiro Maciel

Doutora em Psicologia Social pela Universidade Federal da Paraiba - João Pessoa - PB, professora adjunta da Universidade Federal da Paraiba - Campus I- João Pessoa, PB - Brasil.

E-mail: silcamaciel@ig.com.br

\section{Rita de Cássia Cordeiro de Oliveira}

Enfermeira Sanitarista da Fundação Nacional de Saúde/Suest/PB

Grupo de Estudos e Qualificação em Tuberculose da Paraíba - Grupo TB/PB

Doutoranda pelo Programa de Pós-Graduação em Enfermagem pela Universidade Federal da Paraíba/PPGENF/

UFPB, João Pessoa, PB - Brasil

E-mail: ritaoliver2002@yahoo.com.br

\section{Juliana Rízia Félix de Melo}

Mestranda em Psicologia social pela Universidade Federal da Paraíba, João Pessoa, PB - Brasil.

E-mail: julianarizia@hotmail.com

Endereço para envio de correspondência:

Rua Vereador Gumercindo B. Dunda, 378\1401 - Bairro Aeroclube, João Pessoa, PB - Brasil. CEP: 58036-850

Recebido 4/11/2010, Aprovado 15/10/2011. 


\section{Referências}

Assis, L. P. S. (2007). Da cachaça à libertação: mudanças nos hábitos de beber do povo dâw no Alto Rio Negro. Revista Antropos, 1(1), 1-73.

Barboza, H. B., \& Craveiro, S. (Orgs.). (2004). Pesquisa e intervenção sobre o uso de bebidas alcoólicas. In Na trilha da cidadania: Iniciativas para a promoção dos direitos das comunidades indígenas. (pp. 113-119). São Paulo: Programa Gestão Pública e Cidadania.

Barros, D. R. (2004). Representações sociais de profissionais das áreas de humanas e da saúde acerca do alcoolismo. Dissertação de mestrado, Universidade Federal da Paraíba, João Pessoa, PB.

Camargo, B. (2005). Perspectivas teórico-metodológicas em representações sociais. João Pessoa, PB: Editora Universitária.

Castanha, A. R., \& Araújo, L. F. (2006). Álcool e agentes comunitários de saúde: um estudo das representações sociais. Psico - USF, 11(1), 85-94.

Conceição, J. J. (2007). A percepção dos profissionais de saúde da área indígena potiguara sobre o consumo de bebidas alcoólicas pelos índios. Monografia não publicada Universidade Federal da Paraíba, João Pessoa.

Distrito Sanitário Especial Indígena Potiguara. (2008). Relatório de produção mensal das equipes de saúde dos Polos-Base. João Pessoa: FUNASA/CORE/PB.

Ferreira, L. (2004). O fazer antropológico em ações voltadas para a redução do uso abusivo de bebidas alcoólicas entre os mbyá-guarani no Rio Grande do Sul. In E. J. Langdon, \& L. Garnelo (Orgs.), Saúde dos povos indígenas: reflexões sobre antropologia participativa (p. 90). Rio de Janeiro: ABA.

Brasil. Fundação Nacional de Saúde. (2000). Política Nacional de Atenção à Saúde dos Povos Indígenas. Brasília, DF: Ministério da Saúde.

Brasil. Fundação Nacional de Saúde. (2002). Política Nacional de Atenção à Saúde dos Povos Indígenas. Brasília, DF: Ministério da Saúde.

Brasil. Fundação Nacional de Saúde. (2008). Política Nacional de Atenção à Saúde dos Povos Indígenas. Brasília, DF: Ministério da Saúde.

Guimarães, L. A. M., \& Grubits, S. (2007). Alcoolismo e violência em etnias indígenas: uma visão crítica da situação brasileira. Psicologia e Sociedade, 19(1), 41-51.

Langdon, E. J. (2001). O que beber, como beber e quando beber: o contexto sociocultural no alcoolismo entre as populações indígenas. In Anais do Seminário sobre alcoolismo DST/AIDS entre os povos indígenas (pp. 83-97). Brasília, DF: Ministério da Saúde.
Maciel, S., Moreira, A., \& Gontiés, B. (2001). Representação social sobre drogas e práticas profissionais. In A. Moreira (Org.), Representações sociais: teoria e prática. João Pessoa, PB: Editora Universitária.

Minayo, M. (1984). O conceito de representações sociais dentro da sociologia clássica. In S. Jovchelovitch \& P. Guareschi (Orgs.), Textos em representações sociais (pp. 89-111). Rio de Janeiro: Vozes.

Moonen, F., Maia, E \& Mariz, L. (2008). Etnohistória dos índios Potiguara (2 ed.) João Pessoa: PRPC/SECPB.

Moscovici, S. (1978). A psicanálise: sua imagem e seu público. Rio de Janeiro: Zahar.

Oliveira, M. (2001). Alcoolismo entre os kaingáng: do sagrado e lúdico à dependência. In Anais do Seminário sobre Alcoolismo e DST/AIDS entre os Povos Indígenas (pp. 99-125). Brasília, DF: Ministério da Saúde.

Oliveira, R. C. C. (2009). Representações sociais sobre a situação de vida, saúde e doença na concepção indígena Potiguara. Dissertação de mestrado, Universidade Federal da Paraíba, João Pessoa, PB.

Oliveira, T. M. (2009). Análise psicossocial do preconceito contra povos indígenas de Goiás: contato, sentimentos intergrupais e identidade social. Dissertação de mestrado, Universidade Católica de Goiás, Goiânia, GO.

Organização Pan-Americana da Saúde/Organização Mundial da Saúde (2001). Relatório sobre a saúde no mundo. São Paulo: Gráfica Brasil.

Palitot, E. M. (2005). Parecer antropológico DSEI Potiguara. João Pessoa, PB: FUNASA/PRODOC.

Santos, M. S. D., \& Velôso, T. M. G. (2008). Alcoolismo: representações sociais elaboradas por alcoolistas em tratamento e por seus familiares. Interface - Comunic., Saúde, Educ., 12(26), 619-34.

Souza, J. A., \& Aguiar, J. A. (2001). Alcoolismo em população terena no Estado do Mato Grosso do Sul - impacto da sociedade envolvente. In Anais do Seminário sobre Alcoolismo e DST/AIDS entre os Povos Indígenas (pp. 149-165). Brasília, DF: Ministério da Saúde.

Souza, M., \& Garnelo, L. (2007). Quando, como e o que se bebe: o processo de alcoolização entre populações indígenas do Alto do Rio Negro. Cadernos de Saúde Pública, 23(7), 1640-1648.

Teixeira, M. C. T. V., Schulze, C. M. N., \& Camargo, B. V. (2002). Representações sociais sobre a saúde na velhice: um diagnóstico psicossocial na rede básica de saúde. Estudos de Psicologia, 7(2), 351-359. 